\title{
A eficácia das medidas de recuperação ambiental implantadas em minas de calcário para cimento
}

\author{
(Effectiveness of environmental reclamation measures \\ implemented in cement limestone mines)
}

\author{
Ana Claudia Neri \\ Mestre e Doutoranda em Engenharia \\ Mineral na Escola Politécnica da USP \\ E-mail: anaclaudianeri@yahoo.com.br
}

\section{Luis Enrique Sánchez}

Professor Titular, Escola Politécnica da USP E-mail: Isanchez@usp.br

\section{Resumo}

Esse trabalho analisa a eficácia das medidas de recuperação ambiental implantadas em nove minas de calcário. Utilizou-se o procedimento desenvolvido por Neri e Sánchez (2008), o qual envolve: (i) realização de inspeções técnicas, apoiadas por um roteiro fundamentado nas boas práticas internacionais e nacionais relacionadas à recuperação ambiental em minas, (ii) classificação das evidências encontradas (prática totalmente aplicada ou adaptada satisfatoriamente, parcialmente aplicada, não aplicada ou não se aplica), e (iii) cálculo de índices de conformidade. Constatou-se que as atividades de planejamento apresentaram pior desempenho (baixo índice de conformidade), as práticas operacionais atingiram, em geral, resultados satisfatórios e as de gestão apresentaram nível médio de conformidade. Alguns exemplos de boas práticas são destacados. Conclui-se que as atuais práticas não apresentam boa conformidade com as melhores práticas internacionais e nacionais. Há, principalmente, deficiências de planejamento, com reflexos nas práticas operacionais, em que pese a adoção de várias práticas satisfatórias, especialmente de manejo de solo e de proteção das águas. Não há reconhecimento, por parte das empresas, da importância da gestão do processo de recuperação.

Palavras-chave: Eficácia, recuperação ambiental, minas de calcário.

\section{Abstract}

The effectiveness of environmental reclamation measures implemented in limestone mines is reviewed. An assessment procedure developed by Neri and Sánchez (2008) was used. This tool comprises a set of statements of good practice grouped in three categories (essential, important and accessory practices) which are assessed through (i) carrying out field technical inspections guided by a series of protocols especially designed for this purpose; (ii) classifying inspection evidences according to previously defined categories (totally applied or satisfactorily adapted, partially applied, not applied or not applicable); and (iii) calculating conformity indexes. The results showed that: planning activities featured the lowest performance (low conformity indexes), operational practices reached the most satisfactory results and management practices medium conformity indexes. A general conclusion is that in these mines, current practices are partially effective 
in establishing favorable conditions for long-term success of rehabilitation. Improvements in planning practices could significantly enhance performance and reduce risks.

Keywords: Effectiveness, mine rehabilitation, limestone mines.

\section{Introdução}

O sucesso da recuperação ambiental, em uma mina, não depende apenas da implementação de medidas corretivas ao término das atividades, mas, também, de ações preventivas e gerenciais durante todo o seu ciclo de vida. É necessária a concatenação de três grupos de práticas: (1) de planejamento; (2) operacionais, por sua vez compostas de práticas (i) de proteção e manejo de solo, (ii) geotécnicas e topográficas, (iii) hídricas e (iv) vegetativas e (3) de gestão (Sánchez, 2007).

Planejamento adequado e práticas operacionais e de gestão eficazes são características necessárias para minimizar o passivo ambiental nas minas, reduzindo a exposição da empresa a riscos decorrentes de ações administrativas ou judiciais (Sánchez, 2001) e contribuindo para cultivar uma boa imagem da empresa perante a comunidade e as demais partes interessadas.

Com foco na gestão do processo de recuperação de áreas degradadas (RAD), esse trabalho emprega um procedimento sistemático para avaliar a eficácia das medidas de recuperação ambiental empregadas em minas de calcário para cimento. A comprovação do sucesso de programas de RAD somente pode se dar anos depois de implementadas medidas corretivas, como a estabilização de bancadas ou o plantio de espécies nativas, de modo que é de interesse, tanto das empresas, quanto dos agentes governamentais, conhecer, com antecedência, se as medidas adotadas estão conduzindo ao atendimento dos objetivos de recuperação e uso final da área recuperada.
Assim, o objetivo dessa pesquisa não é o de avaliar os resultados da RAD (e muito menos a exeqüibilidade dos planos de recuperação de áreas degradadas), mas, sim, avaliar as práticas adotadas pelas empresas. Identificando deficiências e pontos fortes dessas práticas, é possível antecipar o provável sucesso de um programa de RAD e indicar ajustes e correções que possam ser adotados durante a fase de operação da mina. A mineração de calcário para cimento foi escolhida devido ao número relativamente pequeno de pesquisas sobre RAD, em comparação com minas de agregados ou de minerais metálicos e à existência de diretrizes específicas oriundas da Cement Sustainability Initiative, da parte de um grupo de grandes empresas de cimento (WBCSD, 2005).

\section{Metodologia}

Para avaliar a eficácia das medidas de recuperação ambiental, nas minas de calcário, utilizou-se o procedimento proposto por Neri e Sánchez (2008), cujo elemento central consiste na comparação das práticas empregadas na mina com as melhores práticas internacionalmente adotadas (benchmark), compiladas, previamente, e organizadas em roteiros de coleta de evidências.

A aplicação do procedimento consiste em três etapas: (i) inspeções técnicas para coleta de evidências, (ii) classificação das evidências encontradas e (iii) cálculo de índices de conformidade.

As inspeções técnicas são guiadas por fichas ou roteiros de campo, que agrupam enunciados sintéticos de boas práticas para cada um dos três grupos (planejamento, operação e gestão). Os roteiros foram publicados por Neri e Sánchez (2008) e compreendem um conjunto de 150 enunciados reunidos em sete roteiros. Antes das inspeções, são solicitados e analisados documentos como estudo de impacto ambiental, plano de recuperação de áreas degradadas, relatórios de monitoramento, procedimentos internos, registros de sistema de gestão ambiental ou outros. No entanto, nem sempre os documentos relevantes são enviados com antecedência e muitos somente são obtidos durante as inspeções e precisam de ser analisados após os trabalhos de campo.

\section{Inspeções técnica para coleta de evidências}

Durante as inspeções técnicas, os analistas, guiados pelas fichas de campo, buscaram coletar evidências objetivas acerca das práticas adotadas na mina. As evidências podem ser de três tipos (classificação modificada a partir daquela proposta por Viegas, 2002):

- Evidência visual (EV): obtida por observação direta; pode justificar uma conclusão sem nenhuma outra evidência.

- Evidência documental (ED): obtida por meio de análise dos documentos, pode ser suficiente para registrar uma não conformidade. Contudo os documentos podem ser mal redigidos ou não refletirem as reais práticas aplicadas; neste caso, o avaliador deve procurar a causa-raiz do problema, visando a identificá-lo - pode haver erros na documentação ou podem ocorrer situações em que as atividades reais tenham sido desviadas dos arranjos planejados.

- Evidência verbal (E): obtida por meio de entrevistas. É menos confiável que as demais categorias, pois o entrevistado pode se limitar a dizer aquilo que deveria ser feito (e não, necessariamente, aquilo que é feito) ou, mesmo, se confundir. É muito importante tratar esse tipo de informação cuidadosamente e procurar confirmar uma evidência verbal buscando evidência visual ou documental que a confirme.

\section{Classificação das evidências}

As práticas são classificadas de acordo com as evidências coletadas. Cada uma das práticas listadas, em cada ficha de campo, foi enquadrada pelos 
avaliadores, durante a inspeção técnica, em uma das seguintes categorias:

- Totalmente aplicada (TA): quando a prática descrita é integralmente empregada na mina.

- Adaptada satisfatoriamente (AS): quando a equipe da mina encontrou uma solução equivalente àquela preconizada pela prática descrita.

- Parcialmente aplicada (PA): quando a prática não é adotada em sua integralidade.

- Não aplicada (NA): quando a empresa não aplica a prática descrita.

- $\quad$ Não se aplica (NS): quando a prática descrita não tem aplicação à situação concreta observada no campo.

\section{Cálculo de índices de con- formidade}

No procedimento de avaliação da eficácia adotado, o tratamento de dados é fundamentado no princípio da hierarquização das boas práticas recomendadas e no cálculo de índices de conformidade, com base nos resultados das inspeções técnicas.

As boas práticas foram hierarquizadas conforme sua importância dentro do contexto do programa a ser avaliado. As fichas já indicam a classificação de cada prática, em três categorias:

- Práticas essenciais: são aquelas imprescindíveis para o sucesso de um programa de recuperação de áreas degradadas na mineração; mediante justificativa bem fundamentada, uma prática genericamente classificada como essencial pode não ser desenvolvida em uma mina (e.g. práticas decorrentes de requisitos legais).

- Práticas importantes: são aquelas que contribuem significativamente para o sucesso de um programa de recuperação de áreas degradadas na mineração (e.g. normas técnicas ou outros documentos de aplicação voluntária).
- Práticas acessórias: são aquelas cuja implementação pode representar melhoria observável nos resultados de um programa de recuperação de áreas degradadas na mineração.

Para avaliar os níveis de conformidade, são calculados os seguintes índices de conformidade: $I_{1}$ (práticas essenciais), I I $_{2}$ (práticas importantes) e I I $_{3}$ práticas acessórias, expressos nas equações (1) a (3):

$\mathbf{I}_{1}=\mathbf{P}_{\mathrm{TA}}+\mathbf{P}_{\mathrm{AS}}+\mathbf{P}_{\text {legal }}+0,5\left(\mathbf{P}_{\mathrm{PA}}\right) / \sum \mathbf{P}_{\text {ess }}+\mathbf{P}_{\text {legal }}-\mathbf{P}_{\mathrm{NS}}$

Onde:

$\mathrm{I}_{1}$ = índice 1 , referente às práticas essenciais.

$\mathrm{P}_{\mathrm{TA}}=$ número de práticas essenciais totalmente aplicadas $\left(\mathrm{P}_{\mathrm{TA}}\right)$.

$\mathrm{P}_{\mathrm{AS}}=$ práticas essenciais adaptadas satisfatoriamente.

$\mathrm{P}_{\text {Legal }}=$ número de práticas exigidas por imposição legal.

$\mathrm{P}_{\mathrm{PA}}=$ práticas essenciais parcialmente aplicadas.

$\mathrm{P}_{\text {ess }}=$ práticas essenciais.

$\mathrm{P}_{\mathrm{NS}}=$ práticas que não se aplicam.

$\mathbf{I}_{2}=\mathbf{P}_{\mathrm{TA}}+\mathbf{P}_{\mathrm{AS}}+0,5\left(\mathbf{P}_{\mathrm{PA}}\right) / \sum \mathbf{P}_{\text {import }}-\mathbf{P}_{\mathrm{NS}}$

Onde:

$\mathrm{I}_{2}=$ índice 2 , referente às práticas importantes.

$\mathrm{P}_{\mathrm{TA}}=$ número de práticas importantes totalmente aplicadas.

$\mathrm{P}_{\mathrm{AS}}=$ práticas importantes adaptadas satisfatoriamente.

$\mathrm{P}_{\mathrm{PA}}=$ práticas importantes parcialmente aplicadas.

$\mathrm{P}_{\text {import }}=$ práticas importantes.

$\mathrm{P}_{\mathrm{NS}}=$ práticas que não se aplicam.

$\mathbf{I}_{3}=\mathbf{P}_{\mathrm{TA}}+\mathbf{P}_{\mathrm{AS}}+0,5\left(\mathbf{P}_{\mathrm{PA}}\right) / \sum \mathbf{P}_{\mathrm{acess}}-\mathbf{P}_{\mathrm{NS}}$

Onde:

$\mathrm{I}_{3}=$ índice 3 , referente às práticas acessórias.

$\mathrm{P}_{\mathrm{TA}}=$ número de práticas acessórias totalmente aplicadas.

$\mathrm{P}_{\mathrm{AS}}=$ práticas acessórias adaptadas satisfatoriamente.

$\mathrm{P}_{\mathrm{PA}}=$ práticas acessórias parcialmente aplicadas.

$\mathrm{P}_{\text {acess }}=$ práticas acessórias.

$\mathrm{P}_{\mathrm{NS}}=$ práticas que não se aplicam.

O passo seguinte é o cálculo do índice de conformidade de cada programa de RAD. Para tanto, utilizou-se a equação (4), onde se calcula o índice de conformidade de cada programa de RAD (IC).

$I C=\left[5\left(I_{1}\right)+3\left(I_{2}\right)+2\left(I_{3}\right)\right] / 10$ 
Após o cálculo do índice de conformidade de cada programa de RAD (IC), é estabelecido o nível de conformidade (NC), conforme os seguintes critérios:

a) Caso o valor do índice de conformidade esteja entre 0,75 e 1 , o nível de conformidade é definido como elevado, caracterizando o conjunto de práticas como adequadas à prevenção de riscos e de impactos adversos e à correção dos principais processos de degradação, com alta adesão às boas práticas internacionais e atendimento aos principais requisitos legais.

b) Caso o valor do índice de conformidade esteja entre 0,40 e 0,75 , o nível de conformidade é definido como médio, caracterizando um conjunto de práticas parcialmente adequadas, mas que devem ser aprimoradas para que se atinja um nível satisfatório de conformidade com as boas práticas internacionais.

c) Caso o valor do índice de conformidade seja inferior a 0,40 , o nível de conformidade é definido como baixo, indicando que poucas práticas são aplicadas em nível satisfatório e denotando baixa adesão às boas práticas internacionais.

\section{Resultados e discussão}

A metodologia foi aplicada em nove minas de calcário em funcionamento há vários anos ou mesmo décadas. Desta forma, as empresas tiveram que adaptar a gestão das minas à evolução da legislação ambiental. No momento dos trabalhos de campo, todas as minas tinham sistema de gestão ambiental certificado segundo os requisitos da norma NBR ISO 14.001:2004. Duas minas tiveram estudos de impacto ambiental preparados para projetos de expansão. Os índices e níveis de conformidade alcançados são mostrados na Figura 1.

Os resultados mostram que o grupo de práticas com menor desempenho é o de planejamento. As práticas operacionais indicam resultados mais satisfató- rios, uma vez que, em seu conjunto, o nível elevado de conformidade foi obtido 17 vezes sobre um total de 36 (47\%). Já o nível médio de conformidade foi obtido 9 vezes (25\%) e o nível baixo foi obtido 10 vezes (27\%). Finalmente, as práticas de gestão obtiveram, em sua maioria, classificação no nível médio de conformidade, sendo que, apenas na mina 2 , as práticas de gestão alcançaram nível elevado de conformidade, tratando-se da mesma mina que atingiu esse nível para as práticas de planejamento. A mina 2, que obteve os melhores resultados para planejamento e gestão, diferencia-se das demais por ter sido recentemente submetida ao licenciamento ambiental (ano 2005), com vistas à sua expansão, tendo sido realizado um detalhado estudo de impacto ambiental.

\section{Práticas de planejamento}

As práticas de planejamento foram avaliadas quanto à sua adequação, sob as perspectivas legal, técnica e econômica. Sob o ponto de vista legal, todas as empresas avaliadas prepararam um Prad (Plano de Recuperação de Áreas Degradadas), o qual foi submetido ao órgão ambiental competente do seu Estado. Em todos os casos, o Prad foi elaborado por consultores externos.
No plano técnico, a maioria dos Prads examinados, com exceção das minas 1 e 2, seguem parcialmente as diretrizes da NBR 13.030 - Elaboração e Apresentação do Projeto de Reabilitação de Áreas Degradadas pela Mineração. Em apenas três minas (1, 2 e 8), foram elaborados estudos espeleológicos da área a ser lavrada e suas imediações. A ausência desses estudos pode representar um risco para as empresas, diante da natureza da rocha calcária, onde se encontram freqüentemente feições cársticas (e.g. cavernas) protegidas pela legislação. Tampouco foram realizados estudos arqueológicos, novamente com exceção da mina 2, devido ao recente processo de licenciamento. Outro estudo pouco freqüente nos Prads foi o hidrogeológico, que deve ser elaborado sempre que a cava puder alcançar o nível freático. Apesar de a maioria das minas já terem atingido esse nível, apenas a mina 2 dispunha desse estudo. Entre as boas práticas relacionadas ao planejamento, destaca-se o planejamento do trabalho de revegetação das pilhas de estéreis com base no mapeamento detalhado das características físicas do substrato feito nas minas 8 e 9. Esse estudo recomendou, com detalhes, ações de revegetação adequadas às condições de cada tipo de substrato.

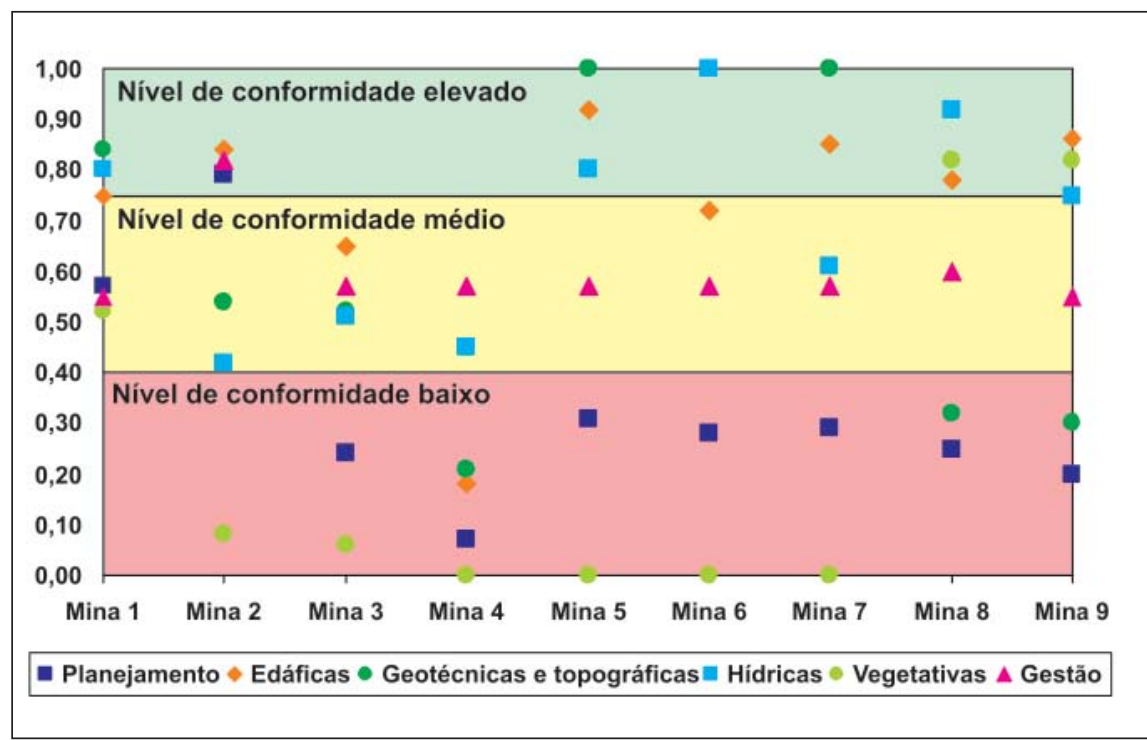

Figura 1 - Resultados da avaliação da eficácia das medidas de recuperação ambiental. 
Ana Claudia Neri e Luis Enrique Sánchez

Sete minas não apresentaram opções de uso final para a cava ou para pilhas de estéril e nenhuma mina apresentou uma previsão para revisão ou atualização periódica do Prad. Nenhuma mina tinha algum documento denominado Plano de Fechamento (PF) ou equivalente. Outra discrepância, em relação às boas práticas recomendadas internacionalmente, foi a total falta de envolvimento da comunidade local nas atividades de planejamento da recuperação ambiental ou do fechamento, uma vez que, em nenhuma mina, havia evidências desta prática.

Apenas na mina 2 havia detalhamento de custos de implantação de medidas de recuperação ambiental durante a fase de operação da mina, mas mesmo essa mina não dispunha de estimativa de custos de fechamento.

\section{Práticas operacionais}

Quanto às práticas edáficas, relativas ao manejo do solo superficial, à prevenção e controle de contaminação do solo e ao controle dos processos de dinâmica superficial, seis das nove minas atingiram nível elevado de conformidade, duas atingiram o nível médio e uma foi classificada em baixo nível de conformidade. Observou-se que, em várias minas, tanques subterrâneos de combustível foram substituídos por tanques aéreos e que as instalações de apoio, como oficinas mecânicas e locais de abastecimento, foram modernizadas para evitar a contaminação do solo. Em todas as minas avaliadas, as vias internas de circulação foram implantadas, em quase sua totalidade, acompanhando as curvas de nível e são dotadas de sistema de drenagem composto por canaletas laterais, geralmente escavadas em solo, e por bacias de retenção de sedimentos. As Figuras 2 e 3 ilustram algumas boas práticas de manejo de solo.

As práticas topográficas e geotécnicas avaliadas são as relativas à estabilidade de bancadas de escavação e de pilhas de estéril. Todas as minas avaliadas aplicam práticas eficazes quanto à estabilidade de bancadas em rocha. Em contraponto, as maiores deficiências encontradas foram relativas à estabilidade de pilhas de estéril. Em especial, notou-se, na maioria das pilhas, que o sistema de drenagem não havia sido dimensionado com base em estudo hidrometeorológico. Além dessa deficiência, notou-se que, em uma das

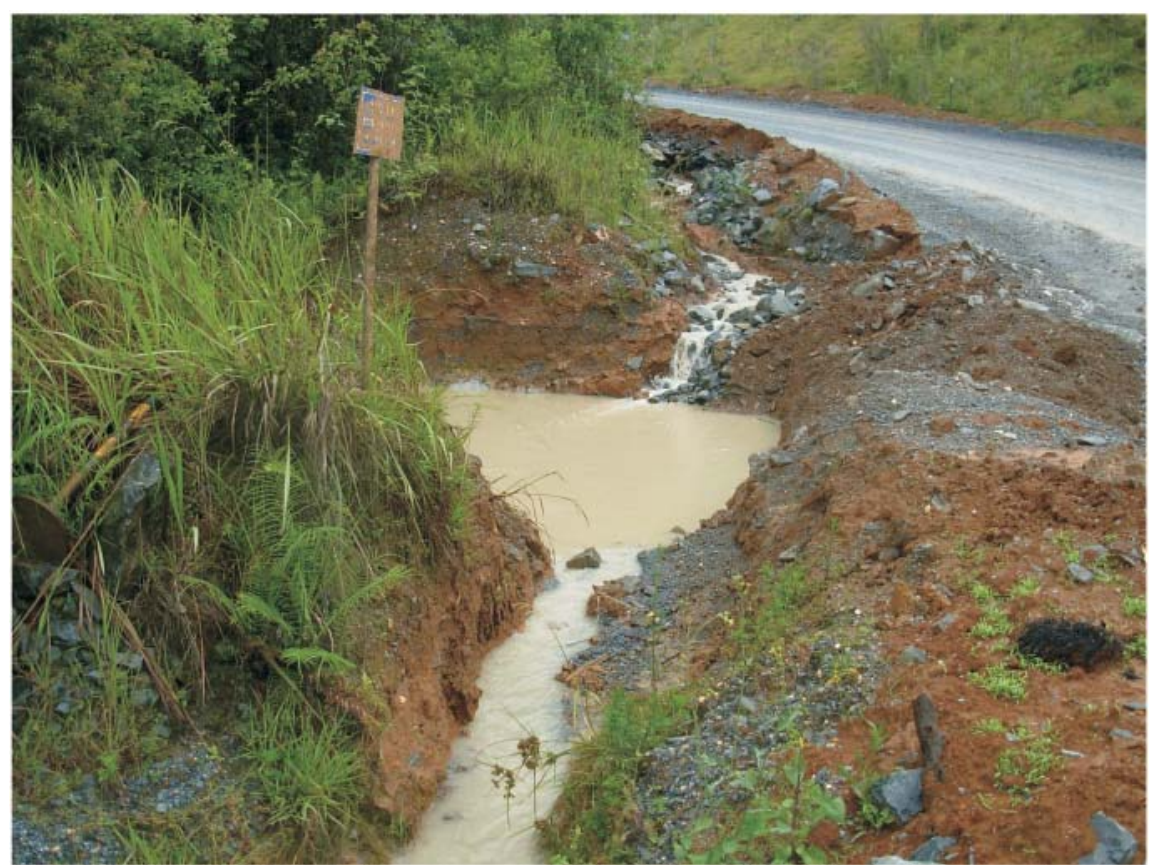

Figura 2 - Sistema de drenagem composto por canaletas e bacias de decantação escavadas ao longo das vias de acesso, para retenção de sedimentos provenientes dos pátios de estocagem, áreas de apoio e vias de acesso (mina 9).

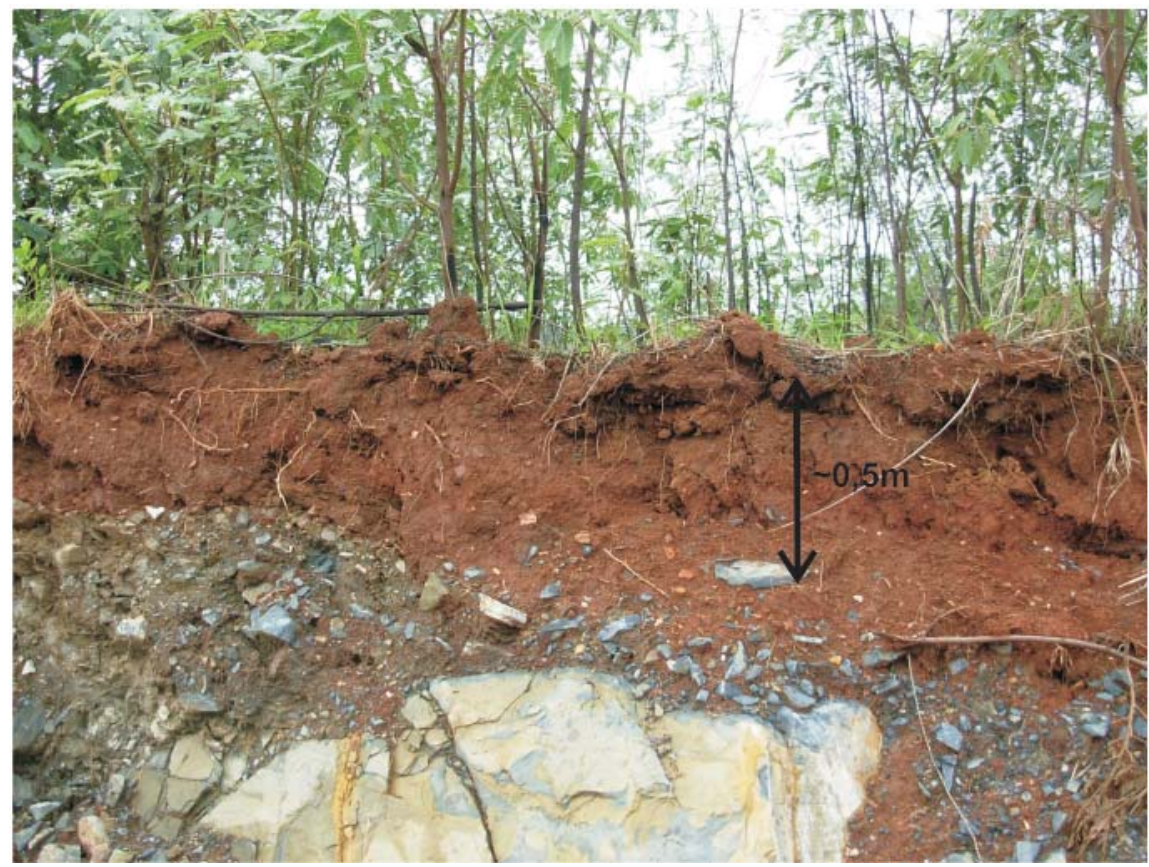

Figura 3 - Corte realizado em área recuperada para abertura de acesso, mostrando-se uma camada de argila colocada para recobrir estéreis e facilitar o crescimento da vegetação nativa. Com o desenvolvimento da vegetação, nota-se o enraizamento das plantas, o que melhora paulatinamente a qualidade do solo (mina 9). 
minas, não foram implantadas canaletas e bacias de decantação. Também não foi implantado qualquer outro disciplinador de escoamento superficial e nem a drenagem proveniente das pilhas de estéril foi direcionada para dentro da cava, de onde a água fosse bombeada e lançada em um córrego. Apesar desse artifício, os sedimentos provenientes das pilhas de estéril estão assoreando maciços arbóreos localizados a jusante. Em uma das minas, uma pequena planície aluvionar de um córrego a jusante de uma pilha funciona como área de decantação, pois não há dispositivo de retenção ao pé da pilha. A Figura 4 mostra parte de sistema de drenagem de uma pilha de estéril com canaletas revestidas, uma prática comum na mineração e que, não somente tem a finalidade de assegurar a estabilidade de pilhas, como também funciona como meio de proteção dos recursos hídricos.

As práticas de caráter hídrico avaliadas incluem aquelas voltadas para a proteção das águas superficiais e subterrâneas. As primeiras estão muito associadas às práticas de proteção do solo e incluem a implantação de sistema de drenagem, que tem, como função disciplinar, o escoamento superficial e a retenção dos sedimentos, evitando, assim, o assoreamento de córregos. Em todas as cavas, sem exceção, o escoamento superficial é conduzido para a cota mais baixa, onde, em muitos casos, aflora o lençol freático. A água localizada no sump da mina é usada, internamente, em finalidades como umectação das pistas para abatimento de poeira, sendo o excedente bombeado e lançado em cursos d'águas próximos, já com baixa concentração de partículas sólidas. Em algumas minas, porém, a drenagem das águas pluviais de parte das áreas operacionais, inclusive de algumas pilhas de estéril, é lançada diretamente em córregos, sem passagem por dispositivos de retenção de sedimentos. Como prática positiva, a mina 1 recuperou a mata ciliar do córrego no qual é lançada a água bombeada da mina, uma prática, tanto de caráter vegetativo, quanto hídrico.

Quanto ao manejo das águas subterrâneas, em todas as minas, a água localizada no sump da cava é composta por uma mistura de água subterrânea e água pluvial. Desse ponto, a água acumulada é bombeada, com a finalidade de criar um ambiente favorável de trabalho. Em todas as minas, parte da água é utilizada para umectação das vias de acesso e outra parte é lançada - em geral após decantação, porém, há exceções - em algum curso d'água das imediações. Em uma das minas, diante da ausência de estudo hidrogeológico, reclamações de vizinhos quanto à possível influência do rebaixamento do lençol sobre nascentes são resolvidas através do fornecimento de água.

As práticas relativas ao manejo de vegetação incluem aquelas utilizadas para a retirada da vegetação, para minimização do impacto visual e, principalmente, para o restabelecimento de vegetação em áreas degradadas. Entre as nove minas avaliadas, nota-se que seis atingiram o menor índice de conformidade, duas se enquadraram no índice de conformidade alto e apenas uma obteve médio grau de conformidade. Esse resultado mostra que ainda são bastante deficientes, ou mesmo ausentes, as práticas relativas ao manejo de vegetação. A maioria das práticas relativas à remoção de vegetação não se aplica as minas estudadas. Uma boa prática vegetativa é exemplificada na Figura 5. Nessa mina, um pátio de armazenamento e uma pista interna foram deslocados da margem do córrego para permitir o restabelecimento de vegetação nativa.

Outro destaque positivo, quanto às práticas vegetativas, fica por conta das minas 8 e 9 , onde o plantio de mudas de espécies nativas é precedido do preparo do solo, mediante a semeadura de gramíneas e leguminosas de ciclo curto, adaptadas às condições climáticas da região, ou seja, principalmente às diferenças de temperatura entre inverno e verão, uma vez que não há, no local, uma estação seca que apresente deficiência hídrica. Esse procedimento permite que o substrato adquira, rapidamente, características físicas, químicas e biológicas mais favoráveis para o desenvolvimento das mudas de espécies nativas. Todas as tarefas relacionadas às práticas vegetativas dessas minas foram planejadas, implementadas e monitoradas por empresa contratada.

\section{Práticas de gestão}

Todas as minas estudadas possuem sistema de gestão ambiental certificado segundo a norma NBR ISO 14.001:2004, o que pode explicar o fato de nenhuma ter recebido baixo nível de conformidade para as práticas de gestão. Apenas uma mina, porém, atingiu nível elevado de conformidade, a mesma que obteve tal nível para as práticas de planejamento e a única submetida, recentemente, ao processo de avaliação de impacto ambiental. A pesquisa de campo mostrou que muitos dos procedimentos de gestão ambiental aplicados nessas minas se referem a atividades industriais ou assemelhadas, como a gestão de óleos usados e o armazenamento de combustíveis e lubrificantes, havendo poucas práticas específicas para recuperação de áreas degradadas ou para a gestão ambiental das minas. Em uma das minas, embora houvesse procedimentos de monitoramento geológico-geotécnico, eles não eram adotados (fato que reforça a importância de usar diversos tipos de evidência durante as inspeções técnicas). Todas as minas faziam monitoramento das águas superficiais, mas nenhuma realizava monitoramento de vegetação ou outros aspectos bióticos.

\section{Conclusões}

A pesquisa realizada mostrou que, de um modo geral, as atuais práticas de RAD não apresentam boa conformidade com as melhores práticas internacionais e nacionais. Há, principalmente, deficiências de planejamento, com reflexos nas práticas operacionais. A necessidade de gestão dos programas de RAD não é ainda reconhecida pelas empresas, que dispõem de poucos procedimen- 
tos específicos de gestão ambiental na mineração, a maioria estando atrelados às atividades industriais. No entanto, muitas medidas de RAD foram ou estão sendo implementadas durante a fase de operação dessas minas e as práticas operacionais alcançaram nível alto ou médio de conformidade.

Um problema que pode ter repercussões negativas no futuro é a alta dependência de consultores externos para todas as atividades relativas à RAD, especialmente o planejamento. Adotando tal política, as empresas são incapazes de obter qualquer forma de aprendizagem organizacional, que possa resultar em maior eficiência ou eficácia na gestão ambiental, e nem desenvolvem competências que possam repercutir no desempenho geral da empresa. Os melhores resultados, para as práticas vegetativas, foram obtidos nas minas $8 \mathrm{e}$ 9 , onde todas as tarefas de planejamento, implementação e monitoramento foram realizadas por empresa contratada.

Dos três indicadores-chave de desempenho para minas de calcário para cimento adotados pela Cement Sustainability Initiative - dispor de plano de engajamento da comunidade, de plano de ação para questões de biodiversidade e de plano de reabilitação -, as minas estudadas somente atendem ao último, que também é uma exigência legal brasileira.

O estudo, também, constatou que as minas submetidas ao licenciamento ambiental, por meio da preparação de um detalhado estudo de impacto ambiental, apresentam as melhores práticas de planejamento e boa conformidade para práticas de gestão, o que sugere que o licenciamento ambiental tem influência positiva sobre a RAD. De modo geral, as empresas estão aplicando práticas parcialmente eficazes para o estabelecimento de condições favoráveis para o sucesso das iniciativas de RAD.

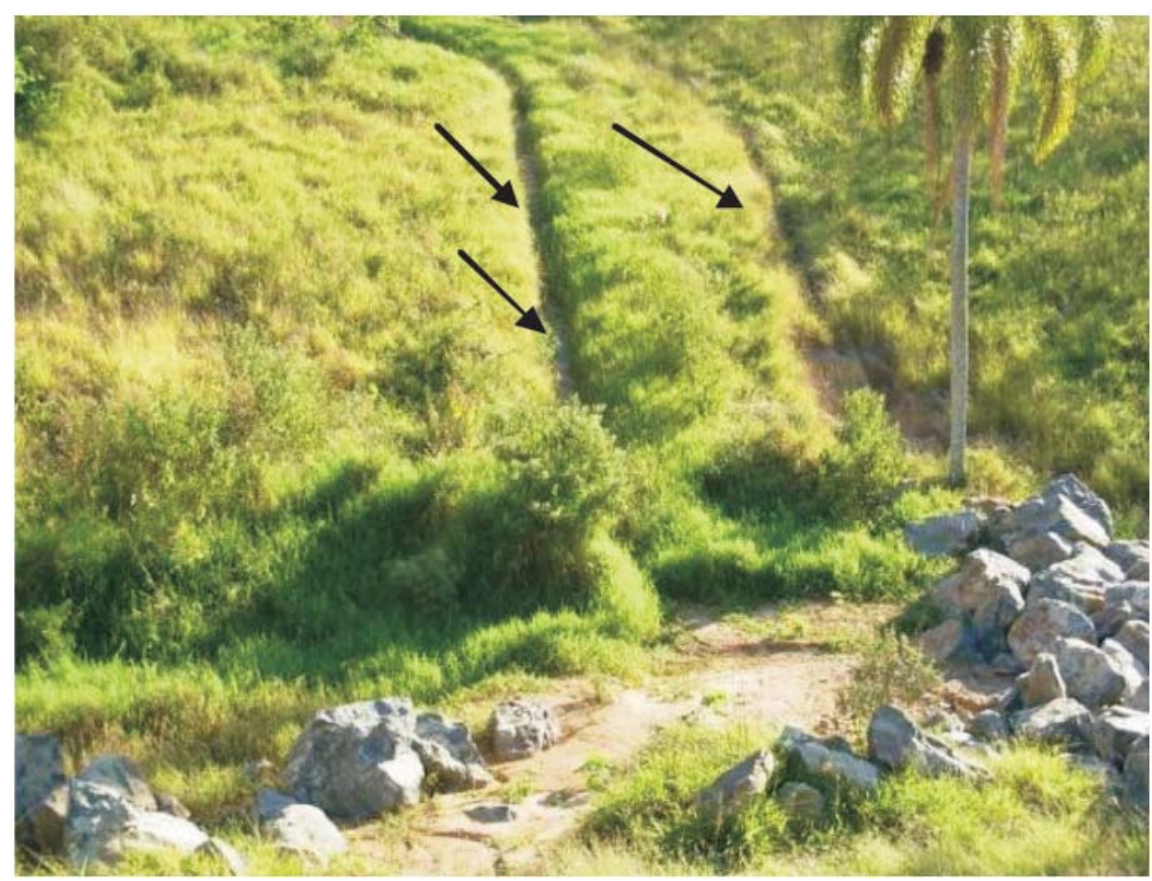

Figura 4 - Parte do sistema de drenagem da pilha de estéril da mina 2, observando-se canaletas revestidas de concreto e bacia de decantação com enrocamento para reduzir a velocidade do escoamento superficial.

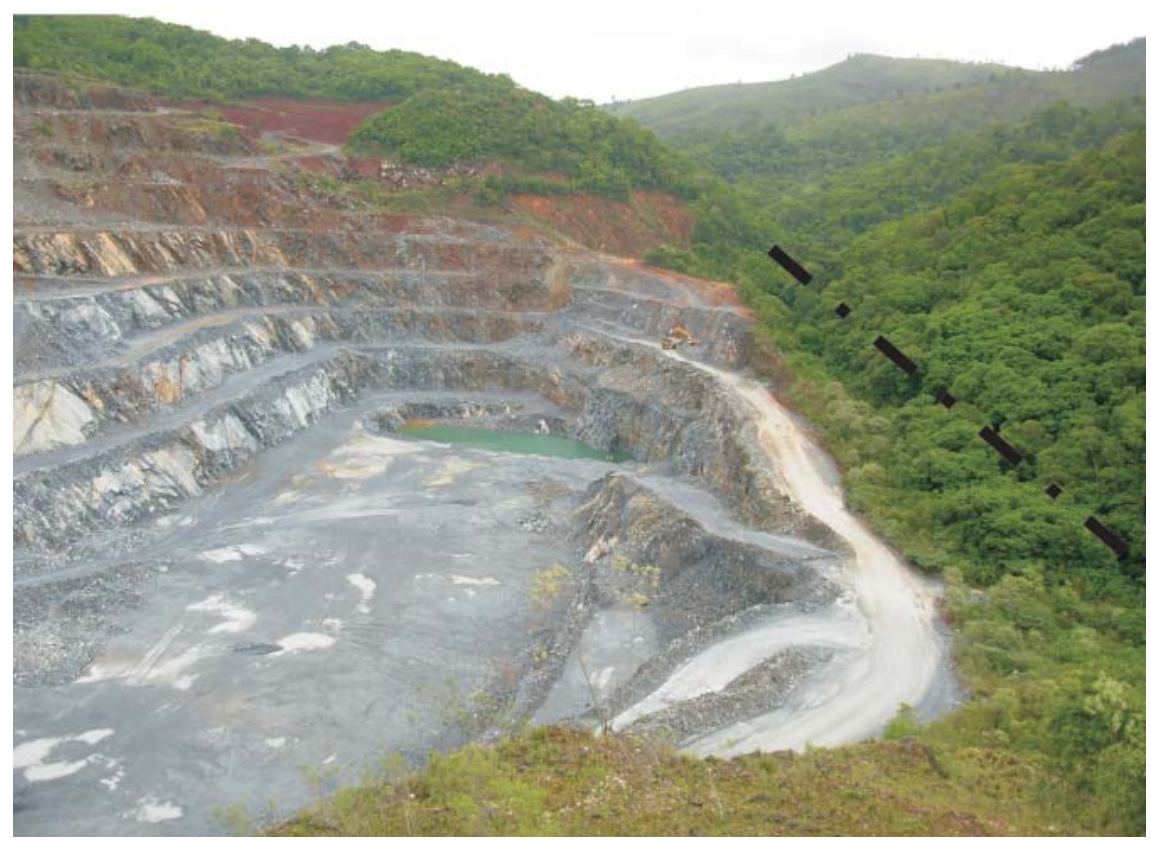

Figura 5 - Área de vegetação ciliar em vias de recuperação situada às margens de um córrego (indicado em preto) e previamente usada como pátio auxiliar da mina 9. Notar, à direita da foto, fragmento florestal integrante da reserva legal da propriedade.

\section{Agradecimentos}

Os autores agradecem à Fundação de Amparo à Pesquisa do Estado de São Paulo (FAPESP - Processo 2005/58089-0) pelo auxílio financeiro concedido para a realização do trabalho e às empresas que autorizaram o acesso e forneceram informações para realização da pesquisa. 


\section{Referências bibliográficas}

NERI, A.C., SÁNCHEZ, L.E. Avaliação da eficácia das medidas de recuperação ambiental em minas de calcário. In: CONGRESSO BRASILEIRO DE MINA A CÉU ABERTO, 5. Anais... Belo Horizonte, 2008. [CD-ROM].

SÁNCHEZ, L.E. Desengenharia: o passivo ambiental na desativação de empreendimentos industriais. São Paulo: Edusp, 2001. 254 p.

SÁNCHEZ, L.E. Planejamento e gestão do processo de recuperação de áreas degradadas. In: FILIPPINI-ALBA, J.M. (org.), Recuperação de áreas mineradas: a visão dos especialistas brasileiros. Pelotas: Embrapa Clima Temperado, 2007. 150 p.

VIEGAS, M. Auditorias de certificação de sistemas de gestão ambiental: um estudo de caso. São Paulo: Escola Politécnica da USP, 2002. (Dissertação de Mestrado).

WBCSD, World Business Council for Sustainable Development, 2005. Cement Sustainability Initiative. Environmental and Social Impact Assessment (ESIA) Guidelines. Land and Communities. Disponível em: http:// www.wbcsd.org, ultimo acesso em 1 Setembro 2009.

Artigo recebido em 10/12/2008 e aprovado em 26/11/2009.

\section{Descubra as muitas informações da:} Geologia, Mineração,
Metalurgia \& Materiais e Engenharia Civil.
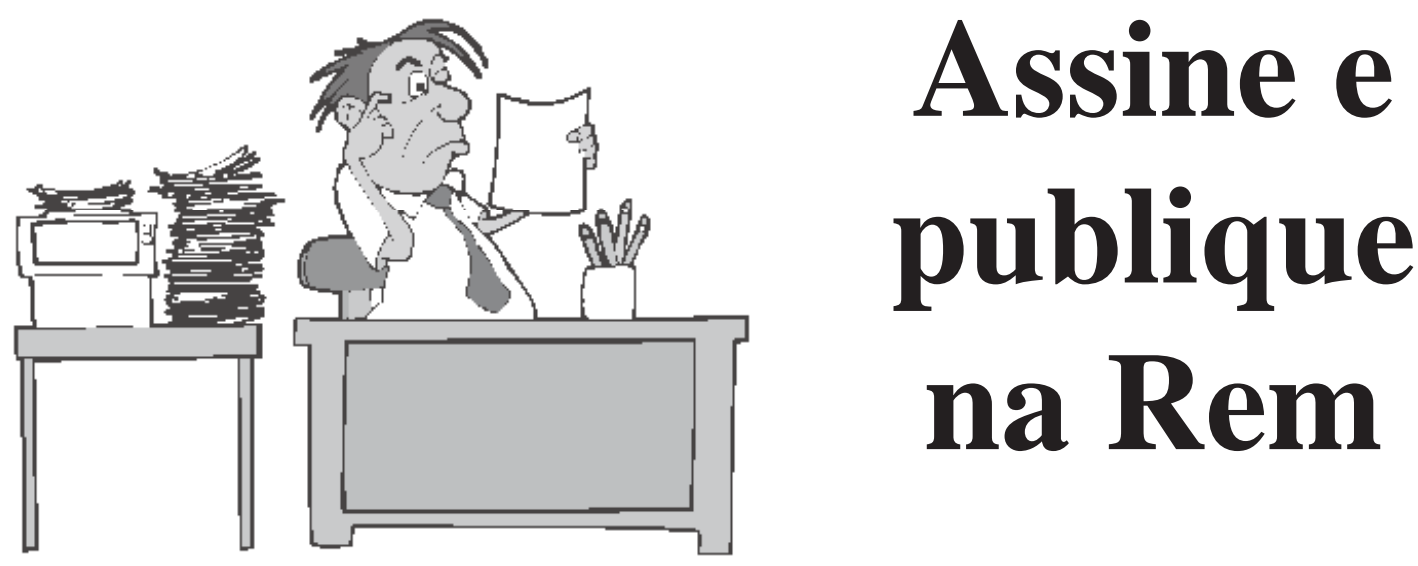

Conheça o nosso site: WWW.rem.com.br 